\title{
14 Protest Suicide in Korean Students and Laborers ${ }^{45}$
}

Protest suicide has a long history in Korea. For example, several scholars died by suicide in 1905 to protest the colonial occupation of Korea by the Japanese (Jang, 2004). In the last thirty years of the $20^{\text {th }}$ Century, nearly 100 people killed themselves in South Korea as a means of political protest (Park, 2004). These fell mainly into two groups: (1) workers protesting the repression of workers and their unions by companies and by the government, and (2) students protesting the government's policies and its cooperation with the United States in the confrontation with North Korea. Some of the protest suicides left suicide notes.

Park (2004) noted that these suicides were not impulsive acts. Sometimes their suicide notes were written a few days before the actual suicide, and the protest suicide was mentioned in the diaries of the suicides months earlier. The decisions were reached after a great deal of reflection and soul-searching. Protest suicides do not appear undertaken by people with psychiatric disorders, but rather are the product of mature reasoning. Since the aim of the protest suicides is to change society, the suicides may be classified as altruistic in Durkheim's (1897) system. Park observed that the suicide notes typically involved a challenge or a message to one's own group, as well as to the powerful group against which they were struggling, a message that more should be done to overcome the wrongs and injustices.

Two samples of notes from protest suicides in South Korea were obtained from the period 1975 to 2003, a period during which South Korea was mostly ruled by authoritarian military leaders. There were 15 notes from workers and 16 from students. The majority of the suicide notes were obtained from two underground compendia (Everlasting Lives) compiled in 1990 and 1998 by the Ad Hoc Committee for the Preparation of a Memorial Services for the Nation's Martyrs and Victims of the Democratization Movement, a committee established in part by families of the suicides. Others were obtained from a variety of sources, including leaflets, newspapers and magazines and from the families of the suicides. These notes are from about one-third of the protest suicides taking place in South Korea from 1970-2003. Other protest suicides either did not leave notes, or their notes were not available. ${ }^{46}$

The two samples of notes (from the workers and the students, respectively) did not differ in sex (93\% and $81 \%$ were written by men, respectively), using fire as a method for suicide ( $80 \%$ and $621 / 2 \%$, respectively), using multiple methods for suicide (33\% and $31 \%$, respectively), or leaving more than one suicide note ( $27 \%$ and $31 \%$, respectively). The two samples of notes did not differ in length (292 and 411 words,

45 This chapter was co-authored with B. C. Ben Park and based on Park and Lester (2009).

46 Where possible, Ben Park visited families to request the original suicide note in order to check the content against the published version. In no case was any editorial change noted. 
respectively). As expected, the workers were older than the students (mean ages 30.7 and 22.3 years, respectively).

\subsection{The LIWC Analysis}

Using t-tests, significant differences were identified for six variables out of the 74 variables examined, no more than would be expected on the basis of chance (see Table 14-1). The differences were in words longer than six letters (students had a higher percentage), prepositions (students had a higher percentage), words concerned with inhibition such as block or constrain (students had a higher percentage), inclusive words such as with and include (students had a higher percentage), job or work words such as employ and career (students had a lower percentage), and music words such as tunes and songs (students had a higher percentage). These differences did not seem to be psychologically meaningful.

Tab. 14.1: Differences between the suicide notes of students and workers (mean scores shown)

\begin{tabular}{lll}
\hline & students & workers \\
\hline Words longer than 6 letters & 21.9 & $17.2^{\star \star}$ \\
Prepositions & 14.6 & $12.5^{\star}$ \\
Inhibition & 0.74 & $0.40^{\star}$ \\
Inclusive & 7.0 & $5.8^{\star}$ \\
Job & 0.7 & $2.4^{\star \star}$ \\
Music & 0.1 & $0.0^{\star}$ \\
Words per sentence & 422.8 & $321.1 \#$ \\
First person singular & 4.1 & $6.1 \#$ \\
Total first person & 6.4 & $7.9 \#$ \\
Tentative & 1.4 & $1.0 \#$ \\
Seeing & 0.3 & $0.2 \#$ \\
School & 1.4 & $0.4 \#$ \\
Leisure & 0.6 & $1.1 \#$ \\
Home & 0.4 & $1.1 \#$ \\
Sexual & 0.3 & $0.1 \#$ \\
Eating & 0.01 & $0.10 \#$ \\
\hline * two-tailed $\mathrm{p}<.05,{ }^{* *}$ two-tailed $\mathrm{p}<.01, \#$ trend (two-tailed $\mathrm{p}<0.10$ ) \\
\hline
\end{tabular}

The notes were also examined for the frequency of specific words using Microsoft Word's icon for Find. The students' notes were protesting against “America” more 
often than were the workers ( $621 \frac{1}{2} \%$ versus $\left.7 \%\right)$ and more often against the "regime" in South Korea (75\% versus 33\%). The students' notes more often mentioned the "minjung" (masses) (69\% versus 7\%) and more often urged reunification of Korea (371/2\% versus $7 \%)$.

The groups of notes from students and workers did not differ in whether they were addressed to parents ( $371 / 2 \%$ versus $40 \%$, respectively), mentioned being sorry (19\% versus $27 \%$ ), asked for forgiveness $\left(12 \frac{1}{2} \%\right.$ versus $20 \%$ ), mentioned being an undutiful son or daughter ( $25 \%$ versus $33 \%$ ), referred to suicide in some way (death, act, leaving, etc.) (69\% versus $60 \%$, respectively), or used a more direct word for death (25\% versus 20\%). As for the emotions expressed, the students and workers did not differ in the mention of any emotion ( $62 \%$ versus $40 \%$, respectively), or anger (6\% versus $20 \%$ ), anguish ( $0 \%$ versus $13 \%$ ) and sadness (25\% versus $13 \%)$.

Thus, the notes of these two groups, students and workers, were similar in the themes expressed. However, the focus of the notes was clearly different. The students were protesting national causes and expressed opposition to the government and America and urged reunification of the Korean peninsular. In contrast, the workers were protesting the practices of their companies and fighting for the rights of the workers. It seems that the tradition of protest suicide in Confucianism has a unique character in modern Korean society. The students appeared to be acting on broad principles based on abstract ideas of national identity opposition to the government. In contrast, the suicide notes of the laborers expressed feelings of injustice existing in the context of their group, and their suicides seemed to invite emotional sympathy from others.

The differences found in these two groups of protest suicide notes may also be an indication of differences in social class. A sense of moral duty, associated with reforming zeal and obligations reflects the elitism that exists among the students. The idea of revenge against their employers, which is more common in the suicide notes from the workers, reflects more context-dependent concerns and is designed to evoke sympathetic reactions from others.

Overall, it seems that, rather than the individual propensity, the protest suicide of both students and workers was affected more by the historical time in which intense socio-political conflict was imposed upon these individuals whose personal identities were acutely disturbed. The historical legacy of protest suicide in Korea and shared collective ideals (i.e., democratization for the minjung, justice and equality for the workers, and reunification of the nation) appear to serve a significant normative force behind the decision to act. These protest suicides seem to have placed a high value on identification with the larger group, and it seems that protest suicide may be viewed as a sacrificial death based on a decision to act demanded by the collective conscience, in the context of a conflict-laden socio-political struggle. If they had been able to develop a more meaningful personal identity that enabled them to sustain enduring attachment to others, they might not have seen their cause as more important than their life. 